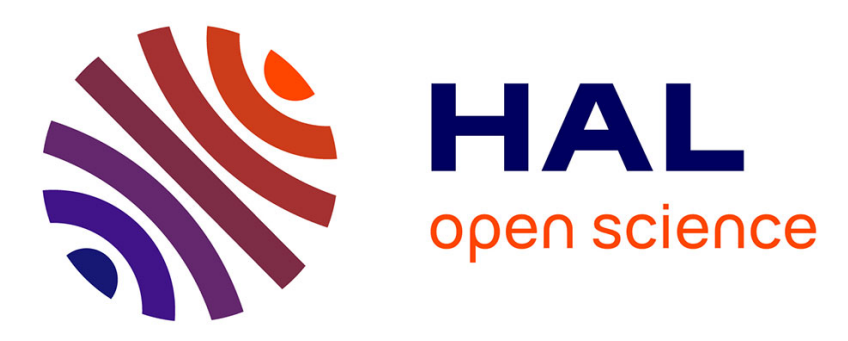

\title{
Decision-making framework methodology: an original approach to project risk management in new product design
}

\author{
Thierry Gidel, Remy Gautier, Robert Duchamp
}

\section{- To cite this version:}

Thierry Gidel, Remy Gautier, Robert Duchamp. Decision-making framework methodology: an original approach to project risk management in new product design. Journal of Engineering Design, 2005, 16 (1), pp.1 - 23. 10.1080/09544820512331325238 . hal-01772658

\section{HAL Id: hal-01772658 \\ https://hal.science/hal-01772658}

Submitted on 20 Apr 2018

HAL is a multi-disciplinary open access archive for the deposit and dissemination of scientific research documents, whether they are published or not. The documents may come from teaching and research institutions in France or abroad, or from public or private research centers.
L'archive ouverte pluridisciplinaire HAL, est destinée au dépôt et à la diffusion de documents scientifiques de niveau recherche, publiés ou non, émanant des établissements d'enseignement et de recherche français ou étrangers, des laboratoires publics ou privés. 


\title{
Decision-making framework methodology: an original approach to project risk management in new product design
}

\author{
T. GIDEL $* \dagger$, R. GAUTIER $\ddagger$ and R. DUCHAMP $\ddagger$ \\ †UTC, Laboratoire Outils d'aide à la Décision pour l'Innovation, la Conception \\ et la production (ODIC), Compiègne, France \\ \$ENSAM, Laboratoire Conception de Produits Nouveaux et Innovation (CPNI), Paris, France
}

\begin{abstract}
There are many different techniques in use today for the identification and evaluation of risks in new product design projects. Once identified, we need to ensure that we treat those risks in an effective manner. This process leads the project manager and his/her team into complex decision-making problems. Decisions to take a risk, reduce the level of risk or to eliminate those risks altogether are left to the project manager's judgement. Given the stakes involved in today's projects, such intuitive measures, based solely on experience, are no longer sufficient. In response to these problems and given the non-repetitive and complex nature of new product design projects, we modelled the decisionmaking process in design in accordance with systemic theories. According to Herbert Simon and his followers, we modelled the way in which the designers use their reasoning and data processing capacities to make decisions. These models, associated with real case studies, carried out on actionresearch principles enabled us to build a method that amplifies our cognitive capacities and allows us to act on the decision-making processes in design. The method involves the construction of a decision-making framework allowing the construction of a robust project satisfying both the project objectives and the team. It is complementary to risk identification methods because it facilitates the decision-making process, in particular decisions related to identified risks, which allows continuous project improvement.
\end{abstract}

Keywords: Project management; Risk management; Decision-making; New product design; Project quality management; Total quality management; Decision research

\section{Introduction}

\subsection{The role of quality in new product design}

A company's capacity to develop new products, at optimum quality, cost and time, is the prerequisite for international competitiveness. However, innovation is by its very nature a risk. Ignoring those risks would be dangerous: this could lead the project team to be affected by hazards without anticipating upcoming events. And if one does not take any risk, it compromises innovation.

This is particularly crucial in case of radical innovation, associated with new technologies, quickly evolving, and with high financial impacts. For those projects, return on experiment is

\footnotetext{
*Corresponding author. Email: thierry.gidel@utc.fr
} 
generally very poor; this is the reason why they are original and sometimes unique. Finally, in those projects, investments are sufficiently important to justify spending time on specific risk analysis.

Our work is dedicated to this type of project, in which risks related to cost, time and performances are important. Our proposals come within the scope of quality approach in the design process. Those approaches provide at the same time a rigorous methodology and a flexible management process. The rigorous methodical organisation structure is needed to give the clients confidence. The flexibility is essential to help the creativity inherent in this type of project.

An essential element in this type of quality in design approach is the management of the risks associated with the product design process enabling the taking of controlled risks.

\subsection{Characteristics of the new product design process}

The complexity of demands associated with products and the environment are such that several solutions to a design problem are possible and there are several ways of reaching those solutions. The principal characteristics of new product design processes are therefore uniqueness, irreversibility, simultaneity and a strong interrelation, rendering them complex in themselves (Genelot 1998, Melese 1990, Paulre 1992: 259-275). Given that every project is unique (ISO10 006), it simultaneously comprises the process for defining the end target and the exploratory route to a satisfactory outcome. Processes in new product design are, with the exception of certain invariable factors, by their very definition new and original for every new product. They must therefore be redesigned and reconstructed with each new project. The design of a new product therefore begins with the elaboration of a design process: before designing a product, we have to design a project.

These phases are among the most critical in the design process, both strategically and economically. By structuring and reformulating the problem, and seeking principles leading to solutions, these initial phases will determine both the strategic guidelines of the project and account for $80 \%$ of the costs of the project, while concurrently only $10 \%$ of total project spending has been incurred.

\section{Evolution in risk management: from performance management to value management}

\subsection{Performance management: on the ascent}

The desire to manage performance, the possibility of improving scheduling and the management of time, costs and design quality have lead to the formal definition of the stages, phases and activities associated with the design process (Maffin 1998: 315). In this light, the classic approaches to risk management advocate the identification and evaluation of risks using predefined and operational project models. Lately, researchers have identified the processes of transformation of information within projects and the associated risks (Gautier 1995). These approaches have enabled considerable progress to be made in the identification of risks and in project management.

However, they come up against two particularly visible limits when the project in question is of high added value, comprising major innovations.

On one hand, the premature formalisation or use of generic project models can be a brake on creativity in projects (Christofol 1995). These limitations engender a loss of value. 
On the other hand, the identification of the risks associated with both the operating and information processes of projects engenders onerous constraints at the decision-making level whereas formerly decisions were made intuitively by project managers without necessarily formalising these risks. The current high performance methods for the identification and evaluation of risks reveal numerous previously unknown risks, and there are insufficient resources to deal with them all (Saaty 1984: 28).

What are the criteria of choice in these conditions, and how does one make the decision to take certain risks, to reduce or eliminate others? Given the stakes involved in new product design projects, performance assessment and recourse to the intuition and experience of project managers no longer seems sufficient.

\subsection{Value management: a paradigm shift}

In response to this dilemma, the study of authors such as Sfez (1992), Roy and Boyssou (1993), Boursin (1996), Munier (1993), Checroun (1992), Kast (1993), Ghertman (1981), Crozier and Friedberg (1977), and Pomerol and Barba-Romero (1993) has enabled us to envisage several possible paths.

The analytic theories of decision-making initially led us to model decision-making through all its phases. In the majority of simple, mono-criteria, convergent cases, the use of positive or substantive rationality emanating from these theories is applicable, as is the principle of efficiency enabling one to attain the optimum. With the use of substantial resources and using appropriate methods, this reasoning can also be applied to complicated cases that have been split up into more simple subsystems.

However, this analytical reasoning has proved in practice to be difficult to apply to the complex situations that one encounters in new product design. (For a better understanding of the difference between complicated and complexity, refer to the definitions of Jean-Louis Le Moigne [1995: 23-26].) Indeed, it is not possible, using current knowledge, to model the decision-making process through all its phases in problems as complex and specific as design projects (Thepot 1988: 8, Therrien Eyquem 1998: 149). It is both an inextricable endeavour, given that there are several a priori satisfactory solutions to a complex problem and several processes for arriving at these solutions, and also a futile endeavour given that each design project is by definition unique, and consequently this modelling would not be fully reusable.

These observations do not prevent us from observing in practice innumerable complex situations that one resolves in a manner held to be adequate by the parties concerned, who put into action a heuristic reasoning (Le Moigne 1974). To arrive at the deduction, we apply the principles of limited or procedural rationality (Simon 1977-1980, March 1991). In these situations, decisions are no longer made in optimum conditions, but in 'satisfying' conditions (Simon 1977-1980); that is to say, the first satisfactory solution is retained.

In accordance with Jean-Louis Le Moigne (1995: 84) and H.A. Simon (1977-1980: 58, 1993: 112, we believe that decision-making can be improved by the substantial increase in human problem-solving capacities in complex non-programmed situations. Rather than favouring a form of organisation that optimises the consumption of resources of the operating system, while remaining unaware of the sometimes intolerable constraints that such a form of organisation can impose on the decision-making system (which, due to the overload of local factors to be taken into consideration, could lead to erratic and even suicidal decisions), it is better to seek to organise the decision-making system in an acceptable, or locally satisfactory fashion, in order to make more effective decisions.

This approach implies a paradigm shift. From a performance management philosophy we have to head towards a value management philosophy (Truchot 1997) (figure 1). 


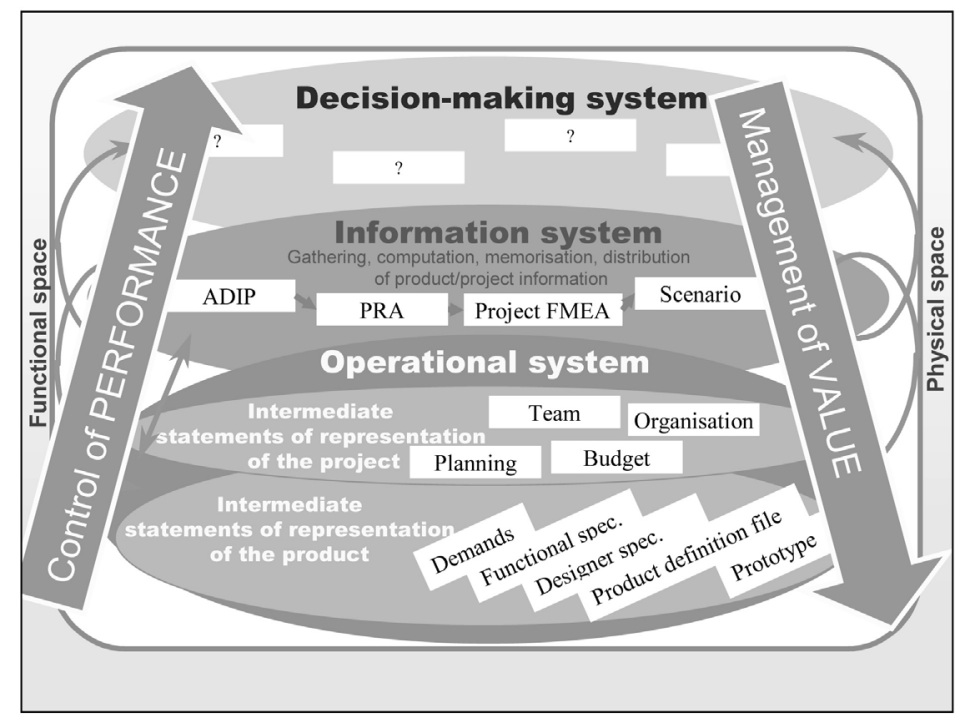

Figure 1. Control of performance versus management of value.

In keeping with this philosophy, operating activities are directed by the decision-making system via the information system and are considered no longer as an end in themselves, but as a means of gathering, processing and circulating information with a view to achieving the targets. Mastery is no longer obtained through the control of production operations or the identification of risks, but by the management of decisions while ensuring their 'effectiveness' (as proposed by Le Moigne [1995], we use efficiency when an optimum can be calculated and 'effectiveness' when satisfactory solution can be obtained); that is, their ability to ensure the progress of the project towards its outcome. It no longer simply a case of ensuring the obtaining of the result, one must also guarantee value.

In this new paradigm, the control of risks is no longer solely ensured by the identification, evaluation, processing and monitoring of risks; it must also begin with the control of the decision-making system with the objective of building a robust project and facilitating its launch -in particular, by rendering risk-related decision-making easier. For a better understanding of this decision-making subsystem, we modelled it.

\subsection{The lessons to be learned from modelling the decision-making subsystem}

The purpose of this modelling work is to identify the factors on which we can act in order to reach a more effective decision. This purpose is in line with Ullman (2001) approach and the concept of 'robust decision-making'. We propose an alternative way to reach a common goal. Once we have identified these factors, we will be able to design a method that, through the construction and organisation of the decision-making subsystem, will create a more favourable context for effective decision-making at all levels of the design process. This modelling work, based on the cognitive precepts of the designers, contributes to the construction of a genuinely person-centred method, which functions as a cognitive amplifier.

We chose to give prominence to the control of the upstream phases of the design process; that is, the elaboration of the programming and organisation of reliable and robust design processes. Indeed, once the pre-project phase is finished and the decision to launch the project 
is made, executive management will entrust the project to project management, who will appoint a project manager.

The first threshold to be crossed by the project manager who accepts to lead the project to completion is to specify the project goals and to propose ways of reaching them. This phase, which we have termed construction of the project, consists of defining how the project, in all its forms, will develop to achieve the final goal. There are two major aspects to this development, which we have termed the intermediate statements of representation of the product and the intermediate statements of representation of the project.

The intermediate statements of representation of the product are often precisely defined and are the technical framework of the project. Starting from the point of view of needs, the project can be defined in the form of a functional specification, a technical specification of needs, product architecture, a full specification, a definitions dossiers, a justification of definitions dossiers, a model, a working prototype, and so on. before arriving at the final production definition of the product, in the form of manufacturing and inspection dossiers.

The intermediate statements of representation of the project seem less easy to define. It is nonetheless essential for the project manager to understand and control the evolution of his project, from the definition of the project objectives, the project team and their development, via the tasks organisation chart, the definition of the project risks and their evolution, as well as the definition of the organisation of the project, the deadlines, the budget, the strategy, document management, communication around the project, and so on, and the evolution over time of all the aforementioned elements.

All these intermediate statements of representation of the product and the project are provisionally defined in the definition phase. The modelling of the decision-making subsystem has enabled us to demonstrate that this construction work took place by going back and forth between the projected reality (i.e. the planned outcome of the project) and perceived reality (i.e. the state of the project as perceived by the project manager and his team). Our method, through the construction of a decision-making framework, enables the facilitation of this definition phase.

Following this definition phase, one moves on to the implementation phase (In actual practice, these two phases overlap and the definition of both the states of representation of the product and project crystallise as the project progresses.) During this phase, the method enables the facilitation, the definition and management of the implementation, and possible redefinition of these forecast statements of representation. Indeed, the previously built decision-making framework can serve as a basis for the redesign work that could result from the revision of the project outcomes or developments in the environment and the situation.

The modelling of the decision-making subsystem (figure 2) enabled us to formulate three hypotheses that we will expand on in section 3.3.

\section{The process of construction of the method}

In accordance with our recommendations concerning projects, we built the method by respecting the principles of management by quality and outcomes. In addition to the taking into account of finalities and the needs of users, five categories of data input contributed to the construction of our method. We chose to classify this design phase data input in order to present it. This classification is of double interest. Initially it facilitates the reading of these elements. Next, we wanted to show that the contributions are on varying levels. For these reasons, in the following we summarise successively: the philosophical approach, which we chose to adopt; the theoretical contributions of decision-making theories and the quality principle; the contribution of the systemic work on the modelling of the design process; the contribution of 


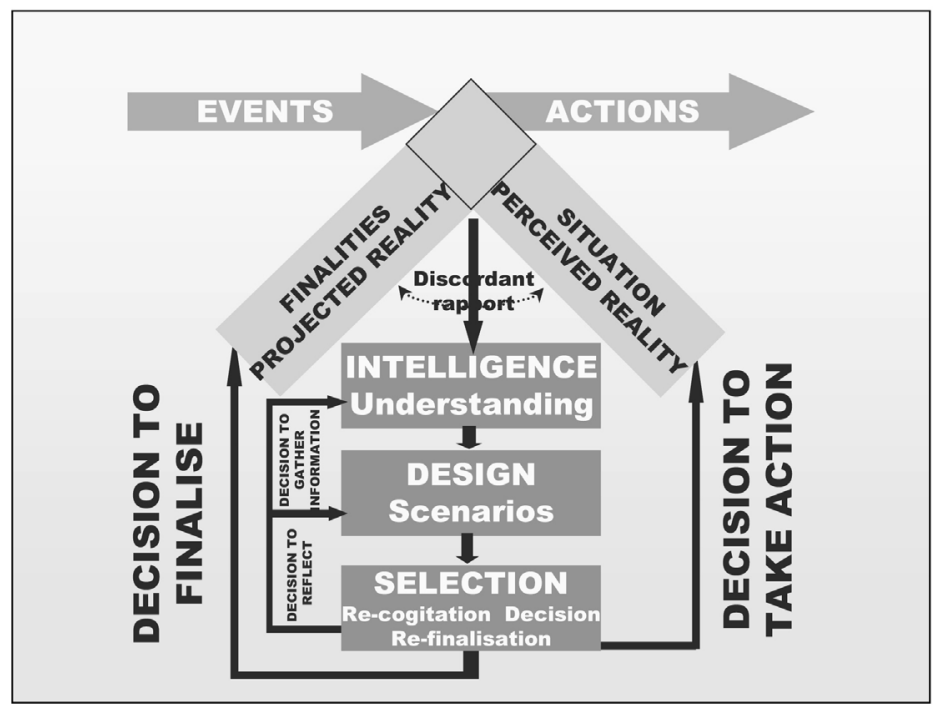

Figure 2. Canonical model of the decision-making process (based on Le Moigne [1995] and Simon [1977-1980]).

experimentation; and, finally, the contributions arising from the study of and comparison with the other existing methods. It should, however, be specified that the borderline between these various categories is not set in stone. In particular, quality principles could be built into the project management methods or risk management methods and vice versa. Furthermore, this linear representation should not lead one to think that we proceeded in a sequential manner, but rather should allow one to grasp the mechanisms used in the construction of our method.

The needs of the players in design projects, in the current context, are to be able to justify their choices, both in terms of product and in terms of project.

In terms of the product, they have to be able to prove that the intermediate statements of representation of the product put forward will ultimately lead to a product that responds to the needs of users throughout its lifecycle, and do so at the lowest cost.

In terms of the project, they have to be able to prove that the intermediate statements of representation of the project defined and the set-up will enable the effective achievement of the project goals.

The end-purpose of our research is the management of the risk of failure in all project processes that contribute to the design of the product. We have demonstrated that in order to preventively limit the risk of failure in the design process it is important to clearly define these processes, and in particular the intermediate statements of representation of the product and of the project.

From the aforementioned we deduced the end-purposes of our method, which are to facilitate and make more reliable the definition of a robust design project, in such a manner that the process enables the satisfactory achievement of the finalities of the project and also satisfies the participants in the design process. This approach must subsequently contribute to the facilitation of the implementation and development of the project.

Following the research work, modelling and experiments carried out, we are able to break the project finalities down into subfinalities.

- A first by-product of the method is to contribute to the definition and structuring of the end-purpose of the new product design project. (Participation in the conception of the strategic process). 
- A second by-product of the method is to enable the definition of the intermediate statements of representation of the product and the project through the formalisation of these finalities on the operational level. This construction operates by taking into account and confronting the previously identified finalities in the perceived situation. The risk of failure to achieve the project finality is studied during this process. (Participation in the conception of the process in relation to the content of the project).

- A third by-product of the method is to enhance communication and comprehension between the parties that formulate the request (executive management) and the team that formulates the response to the request (project management). This is achieved while freeing the creative potential of the participants by the elaboration of a rational framework based on finalities. (Participation in the conception of coordination and communication procedures).

\subsection{Philosophical approach: the constructivist paradigm}

AFITEP (1998: 7) states that 'there is no standardisation of phases that is valid for all projects'. We entirely support this view, and indeed we believe that 'this does not pose too many problems provided that in a project the phases are clearly defined, that all the participants share the same vision of the objective of each of the phases and that all participants have the same perception, at all moments, of the phase in which the project currently is' (AFITEP 1998: 7). We also believe that this shared vision and perception of the project can achieved in the construction of finalities and phases by the participants in the project themselves. This process of construction has additional advantages - it enables all the participants in the project to make the project their own and to express their creativity.

This principle that we retained results from the constructivist approach. This approach led us to work on building a method that could adapt itself to very specific situations we could encounter within companies and regarding the product itself. This point of view contrasts with the positivist approach, which would have led us to adopt a generic method where phases would be standardised and used for a project with a few modification decided arbitrarily by the project director.

However, our intention is not to oppose those two approaches (constructivist and positivist) that our engineering education and training leads us to adopt according to the problematic encountered. We believe that, for the type of projects discussed here, a constructivist approach based on risk analysis is relevant because it gives the project director a tool, risk analysis, to construct a method adapted to a very specific situation and then facilitate its implementation.

\subsection{Contribution of decision-making theories and quality principles}

We wish to highlight three quality principles to take into account during the phases of definition and implementation of projects. They are the principles of the controlled decision-making approach based on the observation that effective decisions are based on a 'logical and intuitive approach to the data and information' (ISO9000 2000), the principle of staff involvement (European Foundation for Quality Management); indeed, the benefits of staff involvement no longer need to be demonstrated. Our research seeks to find out how the method can be used to obtain systematically and concretely this involvement in order to ensure compliance with this principle. Finally, the concept of prevention, one of the founding principles of quality, is a fundamental concept in product design where, given the uniqueness of projects and the irreversibility of most decisions, it is necessary to get it right first time. Our method needs to contribute to the prevention of failures, in the normalised sense of the term ('Preventive action: action taken to eliminate the causes of a potential nonconformity or other potentially 
undesirable situation' [ISO 9000 2000]); that is, the anticipation of all failures in the design process.

In addition to the contribution made by decision-making theories and the modelling of the decision-making subsystem discussed earlier, the systemic theories of decision-making have contributed a fundamental concept, that of limited rationality. The taking into account of this concept invites us to seek not an illusory optimum in a complex situation, but a solution that is both satisfactory to all participants and the most effective given the context.

\subsection{Contribution of the systemic modelling of the decision-making process in design}

Modelling (figure 3) enabled us to make three proposals:

- There are three factors of major influence on decision-making in design.

- It is by objectifying the finalities and the situation that one can improve the decision-making process.

- The symbolic linking of the objectified situation and the finalities enables more effective decisions to be taken.

These proposals, because they result from systemic decision-making theories, which study the way in which man makes decisions, enable the construction of an anthropocentric approach. Based on these proposals, we sought the means of objectifying (i.e. clarifying and classifying) these factors of influence on the decision-making process, then relating them to each other. The elaboration of such a device, which we have called the cognitive amplifier, must enable us to act on the decision-making subsystem and, by consequence, on the information and operation system. This holds true both in the phases of definition and implementation of the design process. We synthesised this contribution in table 1.

During the phase of construction of the design process, the objectification of the situation and the construction of the finalities of the project, the cognitive amplifier facilitates communication and comprehension of the situation and the finalities. This objectification and

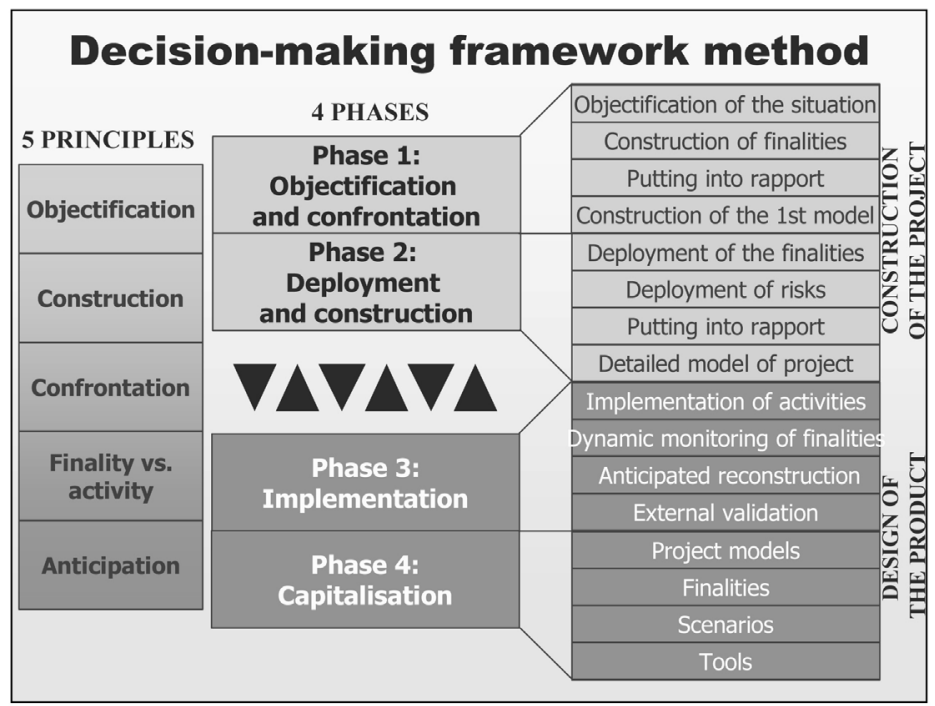

Figure 3. Principles and phases of the method. 
Table 1. The contribution of the cognitive amplifier during the construction and implementation phases.

\begin{tabular}{lll}
\hline & Construction of design process phase & Implementation of design process phase \\
\hline Decision-making system & $\begin{array}{c}\text { Clarifies the finalities and the } \\
\text { situation } \\
\text { Communication and comprehension } \\
\text { by objectification } \\
\text { Information system }\end{array}$ & $\begin{array}{c}\text { Favours effective decision-making through } \\
\text { the finalities/situation framework } \\
\text { Communication and motivation by buy-in } \\
\text { design process }\end{array}$ \\
\hline
\end{tabular}

comprehension are subsequently used as a reference framework for more effective decisionmaking. Moreover, this facilitates the construction and then the implementation of the design processes. Compliance with the processes, which were thus elaborated by the project team, allows for better motivation and facilitates the possible questioning and subsequent rebuilding of design processes.

Four experiments on new product design projects were carried out following action research principles. The systemic model that was developed to analyse those cases that made it possible to validate our assumptions and enhance the model.

\subsection{Benchmarking of other methods}

There are numerous methods for the resolution of design problems (Vadcar 1996, AFAV 1997). We know that a structured approach is the only viable solution that will enable a multidisciplinary team to work together effectively (NF X50-100 1996: 9). Although this is rarely specified, we have observed that the methods for the resolution of design problems utilise the principle of conceptual changes, and the confrontation of finalities (projected reality, thought, abstraction) and situation (perceived reality, fieldwork, concrete facts) that we highlighted at the time of modelling. The fact of clarifying this aspect and demonstrating its importance enables us to justify the necessity of respecting the different phases of the method. It is the prerequisite condition for controlling the transition between the different concepts.

Project management methods clearly specify the interest in 'establishing a reference framework for the project, both in terms of its content, in terms of the processes to be followed to achieve the goal and the means to be implemented; a reference framework that will be used to control the project' (AFITEP 1998: 14). However, when we carried out our research, we did not discover a method that will enable the project manager to 'build' such a project management reference framework (as opposed to establishing or imposing one, as is often implied). Of course, our method uses the existing tools such as GANTT, PERT or their equivalents for the control of planning, organisation, and progress monitoring, as well as for the control of all the continuous processes of a project, to achieve its objectives (ISO10006 1997: 3).

Similarly, project management methods stipulate the importance of project control; that is, the adoption, implementation and use of a system of control linked to the reference framework created, as well as an appropriate set of corrective measures. Here too, the existing methods leave the project manager on his own when confronted with decisions that need to be made due either to the project deviating from its course or changes in the environment surrounding the project. Our method, using as a starting point the construction of the decision-making framework, allows for the definition and subsequent revision of the design processes from a value management point of view. 


\subsection{Contributions linked to project management and risk management methods}

At present, all risk management methods are based on the principle of identification, evaluation and treatment of risks. We propose a different vision that enables the notion of risk to be taken into account from the moment of the conception of the processes in order to obtain robust processes 'right from the start' driven by a pre-emptive value management attitude. Nevertheless, the classic approaches were studied. On the one hand they are perfectly complementary to the proposed approach, and we use them during the implementation phase of a project; and on the other hand they were a major source of inspiration for the elaboration of our method. In particular, the research work of Rémy Gautier (1995) and the Analyse des Dysfonctionnements de l'Information dans un Projet (ADIP) method were at the origin of our research.

\section{The decision-making framework method}

Taking into account design input data, presented in the preceding paragraphs, led us to propose a prescriptible generic method. In order to be able to qualify our method as generic, we chose to present it in the form of five principles, divided into four phases and 16 stages. Associated with each of these phases and stages we have defined objective that must be achieved in order to progress. The achievement of these objectives is verified at various checkpoints. They are the means of implementing and adhering to the principles adopted.

To make this an operational and prescriptible method, certain tools were proposed and tested to achieve the objectives associated with each of the 16 stages. Indeed, project managers have operational needs. The definition of principles and methods would be useless if one was not able to use them in an operational context. It is therefore advisable to propose tools that enable the achievement of the objectives fixed for each of the five phases, although any other tool that enables the achievement of these objectives, provided it enables the adopted principles to be respected, can also be used. Finally, we have made recommendations for implementation based on feedback derived from experience.

The essential contributions provided by the method concern the upstream phases of definition. For this reason, we will essentially describe these two phases. During the phases of implementation and capitalisation, the traditional tools are used, using as a reference the previously built bases.

\subsection{The five principles}

The five principles that we seek to respect during the implementation of the method of process design are the following.

4.1.1 Principle 1: the principle of objectification. As a precondition to any project, it is necessary to build the bases of discussion, the bases on which we will be able to build the project. A shared culture enables collective effectiveness. The principle of objectification allows for the construction of a shared language, it allows for shared conceptualisation, a collective representation, by taking into account all technical, political, organisational, social and strategic elements concerning the project. It must be applied throughout the duration of the project, but it is particularly fundamental in the first phases during the formulation of the design problem. For this reason, it must be applied to the perceived situation of the project. The bibliographic study of the means of objectification led us to study tools in the fields of quality, project management and risk management that we will detail hereinafter. 
4.1.2 Principle 2: the principle of construction of finalities. It seems obvious that the 'identification of objectives is the precondition essential to all projects' (Chvidchenko and Chevalier 1994: 157). However it is a fundamentally different approach to fix objectives and determine finalities shared by all participants in the process (Genelot 1998). We advocate this latter approach.

Laroche and Nioche (1994) remind us that currently the great distinction between the definition of a strategy and its subsequent implementation seems very artificial. Contrary to that which is commonly stated, executive management can not impose a strategy on a company. These observations have led many companies to revise the methods they use to define finalities.

To arrive at an acceptable compromise, it is necessary to carry out a task of construction as opposed to an approach where one 'fixes the objectives and decides to stick to them' and where one seeks to 'convince' and 'justify the finalities' (Chvidchenko and Chevalier 1994: 29). The principle of construction of finalities is an essential condition to obtaining results, in terms of both team cohesion and decision-making. This approach, initially applied to organisations, is transferable to management of projects where similar problems are encountered.

The principle of construction of finalities, which we recommend, can be integrated into a set of different needs, be these strategic, organisational, or emanating from clients or partners.

The respect of this approach makes the application of this principle much less simple. From the starting point of various philosophies, varying expertise and different points of view united in one project, we seek to build coherence (Genelot 1998: 239).

4.1.3 Principle 3: the principle of confrontation. We know that effectiveness is proportional to the participant's acceptance of the finalities of the project. We previously saw that this adhesion can only be secured by the consensual definition of the finalities. The same is true of the project that will have to be implemented in order to achieve these finalities. 'True participation (as opposed to alibi participation) of the staff in the process of redefinition of what must be done, is the basis of success' (Vigier 1995: 70).

The confrontation of finalities versus perceived situation allows for the construction of the project by the different participants. One of the responsibilities of the project manager is to organise the elaboration of the intermediate statements of representation of the project and the product. He must be able to integrate the different resources in the team and communicate with them, get them to participate in the reconstruction of the finalities and the project in accordance with their individual point of view and when confronted with the points of view of others.

4.1.4 Principle 4: the principle of association of activity/finality. By respecting this principle, we are seeking to avoid the 'technician (who) blindly executes his own task and is unaware of the system aspect of the project' (Chvidchenko and Chevalier 1994: 62). Indeed, 'The problem arises from the difficulty, for the persons or groups of persons who carry out the activities that constitute the process, to understand clearly to which process their activity contributes and to construct for themselves a relevant representation of the meaningfulness of their own actions within the overall system of actions. In general these persons are focused on one function, one job, one task, without any particular vision of a process and therefore no vision of the finality of that process' (Genelot 1998: 248).

While respecting the principle we wish to enable the staff to rediscover the finality of their tasks, give them a renewed sense of the result. 'Therein lies the richest and most accessible seam of progress.' We would like to apply these reflections from Serge Vigier (1995: 70), director of total quality at IBM France, to management by project to ensure that all staff 
adhere to and adopt the project as their own. In order to achieve this, during the process of elaboration of the intermediate statements of representation of the project and of the product, which will enable the achievement of the finalities of the project, in collaboration with the entire team, we need to ensure the respect of the principle of association of activity/finality.

4.1.5 Principle 5: the principle anticipation or pre-emption. The permanent reconstruction of the intermediate statements of representation of the project and of the product in the light of the changing finalities and perceived situation is a consequence of the principle of anticipation. This necessitates that the objectification of the finalities and of the perceived situation and the analysis of the risks be revised and enriched regularly.

\subsection{Phases, stages, objectives and checkpoints of our method}

Several methods for the implementation of the principles can be envisaged. We propose one method that can and must be adapted in accordance with the situation and context encountered. The rule is to respect the principles stated.

The proposed method presented in figure 3 was obtained by subdividing the overall objectives of the method into subobjectives for each of the phases and stages. We propose tools that we have adapted and tested, and that enabled us achieve these objectives. It is also advisable to adapt this choice in accordance with the context of the project, the corporate culture of the companies involved, and the background of the individual members of the project team. This flexibility of the method, which does not impose the use of any specific tools, is an asset for the companies and project teams. It is for this reason that we do not wish to impose the means - the only rule is to respect the objectives and principles. However, even if it is not our intention to associate or impose any tools for the achievement of an objective, we recommend, for operational reasons, tools that can be used in each of the phases or stages (figure 4). These tools emanate from the fields of operational safety, risk management, quality, problem resolution, and so on. They are in general already well known by the companies, and often already

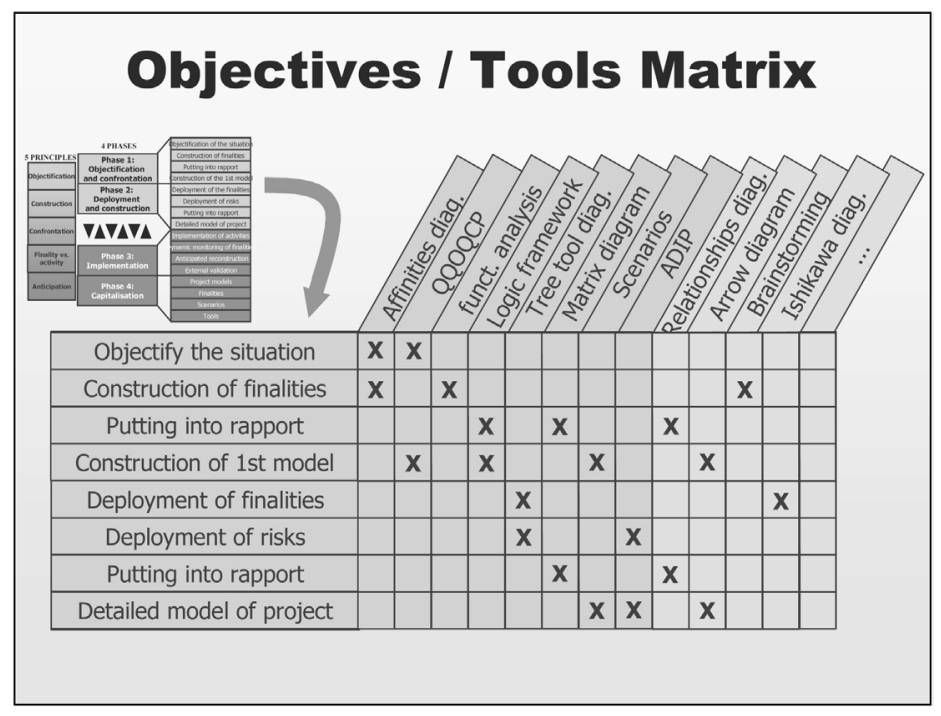

Figure 4. Objectives/tools matrix. 
in use in other contexts, and they sometimes need to be adapted to suit the specific objectives of each stage.

We depict figure 3 phasing in a sequential manner for ease of presentation. Obviously, in reality, the sum total of these activities is jointly carried out over the entire duration of the design process. For example, the capitalisation of knowledge must begin at the start of the project; it can only be achieved at the end.

Conversely, the implementation of the design processes - in particular, the initial research for background information - often begins before the finalities have been fully defined, and these are consequently never totally fixed. The complete set of principles already stated must be respected within each of the phases. When one of the principles is preponderant during a phase, it is generally that principle that gives its name to the phase.

We present in figure 3 the phasing, in its most completed form. The approach that we advocate the use of during the elaboration of and monitoring of a project comprises four phases.

The two first phases are dedicated to the construction of the design processes. To highlight this reflexivity, we refer to them as phases in the construction of the project itself. During these phases, which are at the core of the method, we use tools that emanate from the fields of quality and risk management to objectify the context and construct the finalities of the project, then subsequently to juxtapose them before their final deployment.

The next two phases correspond with the implementation of the design processes; that is, the physical design of the product and the capitalisation of know-how or operational feedback.

We will now detail these phases and stages.

4.2.1 Phase 1: objectification and confrontation. This phase has two objectives: formulating the problem and constructing a shared systemic decision-making framework. To achieve these objectives we have to:

1. enable the project team to share a shared vision of the finalities of the project, the criteria of achievement of these finalities and a degree of freedom;

2. get all participants in the process to become aware of the perceived situation;

3. evaluate the potential risks through a symbolic association, the confrontation of the finalities and the situation; and

4. determine the information/action/organisation/resources necessary to the limitation of these risks (hierarchy and classification of risks).

At the end of this phase, we have to have an explicit and shared vision of the project in the form of a model and a decision-making framework (Russo and Schoemaker [1994], researchers at the Center for Decision Research at the University of Chicago, demonstrate the importance of decision-making frameworks during the decision-making process). In association with this model, we have produced a list of risks.

4.2.1.1 Stage 1: objectification of the situation. The elements used for the objectification of the situation are the following.

1. The general concept of the product, the needs, the principal services expected.

2. The reasons for the choice of this project and the strategy, the corporate ambitions and the stakes associated with the product to be designed and sequels to the project.

3. The material and human resources available as well as the available information (similar studies already carried out, etc.). The definition of the responsibilities and roles of the participants. 
4. The premises, distances, schedules, deadlines, budget, etc.

5. The partners concerned, by the progress or result of the project.

6. Any limits or constraints in terms of organisation, procedures, legislation, corporate culture, internal or external communication, confidentiality, etc.

Above and beyond the clarification and exposure of these elements, there is also a need to get the members of the project team to take a perspective and help them to construct a common and complete representation of the situation that takes into account the perceptions of each person.

In order to objectify the situation, we used the 6W (What, Who, Where, When, Why, hoW; Chauvel 1996, Perigord 1997). This tool is one of the seven leading tools in quality management. It enables the structured gathering of information and an initial processing of the data through the answers to a set of simple questions. The result of the implementation of this tool is twofold. First, a concrete result in the form of an explicit cartographic view of the situation, such as it is perceived by the members of the project team. Next, the dialog started during this implementation enables the confrontation of different points of view within the group, which engenders cohesion and encourages members of the group to take a perspective on the situation such as it is perceived by each of them.

4.2.1.2 Stage 2: construction of the finalities. The objective of this stage is the construction of finalities shared by all the participants in the project, which encapsulates the points of view and needs of the customers of the product as well as the project.

During this stage, the participants need to analyse their own objectives in order to construct a set of meta-finalities shared by the entire project team. These finalities need to be structured, organised, and hierarchical. It is important to take into account, during this stage, the finalities in terms of the performance of the product or service to be designed, the results expected, the degrees of innovation acceptable or desired, as well as the project finalities, in terms of communication, risk-taking, monitoring, and so on.

To achieve the objectives of this stage, we need to carry out a form of semantic data processing operation, an analysis of the data verbally expressed by the participants in the design process. For this reason, we recommend the use of the KJ method in four parts. The KJ method was invented by Professor Kawakita Jiro - the affinities diagram is a high-performance tool for the structuring of group reflection, based on factual and concrete elements emanating from the experiences of participants. This tool enables the regrouping of observations objectified 'by affinity', without recourse to any preconceived logic. These groups are then given titles, thereby giving meaning to these observations (Shiba, 1995b). The room and equipment necessary for the sessions have to be prepared in advance by the moderator in accordance with the directions of the method.

- First part. This consists of each member of the group briefly expressing their perception of the project finalities. These can be expressed positively in the form of objectives or negatively in the form of constraints. After this presentation, the moderator writes the theme of the affinity diagram on the board. We used the following question: 'What are the finalities of project XXX?' The participants in the project then write a list of finalities on post-its.

- Second part. The group then agrees on a complete list of finalities. This sometimes fastidious phase enables a semantic cleansing through the reformulation of the finalities by the members of the group who did not write them. At the end of this operation, all the participants should agree on the same meaning for the finalities and should recognise their pertinence. The finalities are then regrouped by affinity. This is a vital step in the process, which enables everyone concerned to discover and understand the meaning of the regrouping used 
by the other members of the team. It also enables the rectification of potential omissions through the addition of new finalities.

- Third part. The finalities, regrouped by affinity, have to be given a higher level name that expresses the shared meaning of the finalities as perceived by the group. This operation is important for the work of construction of the finalities. This process of regrouping and construction of a title is repeated until there remain five meta-finalities or less. Links or relationships (cause/effect, contradiction, etc.) are proposed between the different finalities and then the diagram is deployed.

- Fourth part. The hierarchical level of the finalities is determined and then these are framed in accordance with their affinities and linked to each other using logical links. The participants have to evaluate the respective importance of the second level finalities by a weighted voting system, each person having to choose the three most important finalities for him and grade them hierarchically.

The meeting ends with the construction of a phase that synthesises the work done, giving a summary expression of the finalities at the core of the project.

We can observe that the affinity diagram enables the methodical processing of verbal data (Shiba 1995b). It deepens and enriches the meaning of the language. Kawakita Jiro, the creator of this method, teaches that one should listen to 'the words that correspond to the data of everyone's personal language'. Among the principles evoked earlier, those of construction and objectification are respected by the utilisation of the KJ method: during the structuring and regrouping of finalities by affinity and during the search for meta-finalities, a task of construction is demanded from the participants who have to abstract a shared meaning from several elements of linguistic data. During these phases, we observe a change in the perception of these finalities by all participants. This construction of a set of shared meta-finalities is one of the pillars of the decision-making framework of the project.

Finally, during the definition of the links and relationships between these finalities, awareness is enhanced; an overview of the finalities that facilitates their hierarchical classification during the third and last phase comes into being.

To end, these finalities have to be summarised in their highest level of abstraction, in a phase that requires the consensus of the group, reflecting a shared vision constructed by the group and obtained by the implementation of the principle of objectification.

Other tools can be used to achieve the same objectives; in particular, we tested the method of the logic framework, the principles of functional analysis method applied to the construction of the finalities. We also envisaged the use of cognitive cards.

The elements emanating from these two first stages can be synthesised into a clarification memorandum drafted by the project manager and approved by executive management.

4.2.1.3 Stage 3: the finalities versus situation confrontation. The objective of this stage is to identify the risks of non-achievement of the finalities, and in particular to enable the participants to share a common vision of these potential risks, of their causes and effects. A preliminary risk analysis is carried out based on the elements that define the perceived situation of the project that arose from the first stage and the finalities constructed during the second stage. This ensures the symbolic confrontation of these elements. This stage enables one to ensure that the finalities are appropriate for the situation, and to evaluate by a symbolic rapport the distance that separates the current situation from the hoped for situation. Depending on the obstacles or risks brought to light, a deeper study can be made; the study of their causes and effects carried out and a synthesis drafted. Lists allow for the classification of risks, in accordance with their relevant typologies. 
The confrontation, the symbolic relationships between the objectified elements, can be obtained using other matrix-type tools that we can adapt to the circumstances. These tools are, for example, matrix diagrams (KJ method). Creative tools can also be used to identify the risks; this task can also be supplemented by the use of a checklist of risks.

4.2.1.4 Stage 4: First model of the project. The objective of this stage is the conception of an initial model of the intermediate statements of representation of the product and the project, to enable achievement of the finalities according to the perceived situation and the list of all risks identified.

These statements of representation are subsequently validated by the project team and, depending on the case, by senior or executive management. The modelling of the intermediate statements of the product and project can be carried out using different methodologies. In order to achieve this, we use the data derived from the three preceding stages.

Summary forms are produced. They begin with the formulation of the problem, the finalities of the project, the associated risks. The modelling of the intermediate statements of representation of the product enables the elaboration of a first phasing. In association with this key stage, the modelling of the intermediate statements of representation of the project enable the definition of the structure of the project, its organisation, the project team, the information system, the material and human resources available, the responsibilities, and so on, and their evolution over time.

4.2.2 Phase 2: deployment: from finalities to action. The goal of this phase is to set out the overall finalities on theoperational level, then to convert these into actions. This results in a detailed model of the project, with an associated list of risks. Initially, the overall finalities are set out, and phases and reference points are identified just as a classic design operation. However, these phases and reference points are expressed not in terms of specific actions to be carried out or intermediate returns, but in terms of finalities to be achieved, associated with identified resources and constraints. The achievement of the finalities of a given phase 'specification of needs' can then be accomplished on the operational level in a number of manners: using for instance a functional specification, a prototype model or any other creation that satisfies the objectives assigned to this phase. Subsequently, the different tasks required to achieve these objectives are itemised and managed using the traditional project management tools.

The objective of this phase is therefore to translate the intermediate objectives into action plans. For this, it becomes necessary to refine the first model, based on the general objectives, in order to arrive at an operational model of the project.

4.2.2.1 Stage 1: deployment of the finalities. The objective of this stage is to deploy the overall project finalities in the form of operational objectives. Several manners of proceeding can be used. A functional analysis can be used to determine the functions of the processing of information from the different possibilities of project model. The functions of the process are then broken down, as recommended by ADIP, into three components: gathering, processing, and transmission of information. To each of these components, there is a corresponding basic function of the process (information).

One can also use objectives deployment tools emanating from the fields of management by objectives or by methods such as HOSIN (breakthrough management) or quality policy deployment (SHIBA 1995a). 
4.2.2.2 Stage 2: deployment of risks. The objective of this stage is to determine the modes of failure of each processor, as well as their causes and consequences. Problem-solving tools such as the Ishikawa diagrams, brainstorming and the KJ method are used. Databases of modes of failure are available to render this task more thorough.

We are currently studying the possibility of using other tools, such as the tree tool diagrams, to assist in the deployment of the finalities and risks in the operational arena.

This manner of proceeding enables the identification of the risks associated with each of the basic operations, as well as the transversal risks associated with the project, its organisation, and so on.

4.2.2.3 Stage 3: confrontation. The symbolic linking of these elements on the operational level enables their shared deployment and leads to an operational project model.

In order to carry out the deployment, we can use the AMDEC project as recommended in the ADIP method (Gautier et al. 1997). This method enables the identification of the information processors (gathering, processing, and distribution) and of associating the dysfunctions linked to this information that were brought to light.

Once these potential failures have been identified, one must find the means of eliminating them, reducing, or simply accepting them. We propose a method for dealing with these risks through a confrontation between the identified risks and the expected profits or benefits. This leads to the search for an acceptable compromise formalised within a project scenario.

The objective of this stage is to analyse the basic functions in the process of treatment of information (the information processors) in accordance with their modes of failure, and their effects on the project (in terms of product qualification). This operation is carried out using a table similar to that used in the AMDEC project.

4.2.2.4 Stage 4: detailed modelling of the project processes. The preceding stages enable the construction of a principal scenario, and if need be alternative scenarios. These scenarios comprise the actions necessary for the implementation of the totality of processes related to the project: processes related to the design of the product, but also processes related to management of deadlines, costs, human and material resources, communication, quality management and the strategy adapted to the context of the project. To these scenarios are associated lists of risks to be monitored (Louyot 1997).

Generic design models such as those proposed by Aoussat et al. (2000) and Yazdani (1999) could inspire designers, who will adapt them in accordance with the general finalities and risks. The criteria for the evaluation of these projects and their modes of application are then defined in order to verify the appropriateness of these models with the finalities of the project. The organisation surrounding the project is also validated. This phase ends with the elaboration of a detailed principal scenario accompanied by alternative scenarios (Louyot 1997), associated with a list of risks to be monitored.

As pointed out by Frost (1994), Hubka and Eder (1996), Eder (1998) and Maffin (1998), generic design has to be adapted to actual situation and organisational context. All the preparatory work carried out in the first two phases enables this adaptation and the construction of a decision-making framework that facilitates the process of deciding whether to take risks, take action to reduce the causes of risks, take action to reduce the consequences or take action to improve the detection of risks. The available data concerning the finalities, the criteria of satisfaction, the situation, and so on, can facilitate the use of mathematical decision-making tools. However, as stated in the standard NF X50-105 (1991: 11), one must not lose sight of the fact that in project management 'the appreciation of risks and trends is more important than knowing the exact figures'. 
4.2.3 Phase 3: implementation of the project. The permanent reconstruction, the communication, and the revision of the finalities of the project are naturally important throughout this phase. However, communication and the update of project processes are also important in order to enable participants to be able to position themselves and obtain the relevant information.

The elaboration of 'dashboards' enabling the dynamic monitoring of projects in a manner analogous to that which is actually happening in production can also be used (AFAV 1997: 197).

The monitoring of the progress of the project requires regular meetings for validation. Validation can take place on two levels. Intra-project validation verifies that the project is progressing as planned, in terms of finalities, efficacy of the planned actions and project presents failures.

External validations are often termed project reviews and are carried out with executive management at the end of major stages in the design process. These allow for the evaluation of the progress of the project. During these project reviews, modifications can be made to the finalities of the project when management observes, or decides on, a variation in means or strategy. If the design choices were explicit and clearly communicated, having taken into account the finalities, the demands and the situation, their validation is often rapid. However, if the heuristics that lead to these choices cannot be demonstrated, the subjective judgement of the decision-makers can call these choices into question. Such a situation transforms these validation meetings into design session, which is neither desirable for the design team that sees its work called into question nor for executive management that finds itself undertaking a task outside its sphere of responsibility. The implementation of our method enables the avoidance of this form of dysfunction and helps to convince executive management that the choices made are relevant and effective in relation to the finalities of the project. This can only be achieved by demonstrating that the processes implemented (procedures, monitoring, calculations, etc.) enable progress towards these finalities to be made.

If a dysfunction is nevertheless identified, a precise diagnosis is made, enabling the implementation of curative and corrective actions.

4.2.4 Phase 4: capitalisation. During this phase, we extract and analyse the contributions brought by the project so far; in particular, concerning experience in terms of new project models, alternative scenarios, objectives and risks. This enables us to supplement the corresponding databases. The methodological expertise acquired is also added to the corresponding objectives/tools database, which includes a section on interpretation and adaptation of tools. The diagnoses made during the identification of dysfunctions and their associated remedial actions can also be capitalised for use in future projects.

\subsection{Recommendations for implementation}

As previously stated, the proposed method seems simple but its implementation is delicate. As demonstrated by Françoise Darses (1997: 17) through her research, 'gaining knowledge of elements of the problem that appear obvious is not a simple matter: one frequently observes how little the participants in the design process know about each other's objectives'. The efficacious implementation of the method first necessitates knowledge of the concepts used, the principles, and the method that has to be understood. Next, one needs a degree of comprehension of the mechanisms implemented. A comprehension of why the principles and method were adopted enables the participants to appropriate them. Finally, it is necessary to personalise and adapt the method to the situation without betraying the original spirit, principles, and concepts. 
The simplicity of the method is therefore merely an appearance, and unchecked departures from the method will bring about an irremediable deterioration in its effectiveness. Each phase necessitates preparation (training, information) and a certain reasoning (by finalities, in functional terms, in terms of solutions, etc.).

Beyond the method, as stated by Jean Chachuat (1998), p. 8 'the full power of risk management is obtained when a relevant approach is implemented by a multi-disciplinary team, whose expertise matched the objectives targeted'. One needs to ensure the active presence of the essential experts. To achieve this, the participants must be chosen at the right level of responsibility. Sufficiently high for them to be representative of the different dimensions of the job and for them to have the decision-making autonomy necessary for the team to complete the task it sets itself. However, sufficiently modest for them to attach importance to the operational running of the project and for them to acknowledge this as one of their objectives.

'The role of the facilitator is vital when it comes to choosing the right level of analysis and retaining control of it [...], promoting a frank and open climate, conducive to exchange [...]' (Chachuat 1998). The facilitator must promote a participatory approach, based on the values of total quality such as delegation, empowerment, teamwork, and so on.

In this context, the training of the participants in the project proved vital in making them aware of these new modes of reasoning and approaching design. The heightened awareness of risks and opportunities, the reasoning by finalities, the decision-making process, and the principle of limited rationality help to overcome any initial reticence. This also contributes, within the team, to a homogenisation of the perception of risk.

The structure of a project evolves and changes, because in a project the finality takes precedence over the structure (Genelot 1998: 239). All energies are focused on the accomplishment of the finalities and this generates a tendency for projects to be self-organising. We believe that a system of organisation by project cannot be decreed by a management decision. In the same way that the processes of the project have to be constructed and reconstructed to face change, so the implementation of a system of organisation by project needs to be done progressive through successive modifications that will lead it, at varying pace, to reach degrees of maturity. 'One could say that the enterprise migrates from a rigid and strict form of organisation to a system of controlled autonomy or, in other words, migrates from "solid state" quality to "liquid or malleable state" quality' (Laplane 1995: 59). This learning experience is all the more important where management by project rests on a set of values such as empowerment, delegation, inter-professional solidarity, transparency, recognition of the right to make mistakes, and so on. We therefore do not choose a form of organisation - we build it on the foundations of this set of values, and we ensure that it fosters the right conditions for teamwork. This approach of organisation by project is one of the reasons that led us not to conduct more extensive research in this area. Furthermore, this field has already formed the basis of numerous studies in industrial engineering, quality, and management sciences that we used as reference (Giard 1993, AFAV 1997: 55, AFITEP 1998: 16-21, Genelot 1998).

\section{Implementation of the method: review}

The objective of our research is to produce a prescriptible method. Hervé Christofol (1995) proposes three criteria for the evaluation of such a method: adaptability, operability, and creativity. We will now proceed with a review of our method in the light of these criteria. Then we will evaluate its capacity to mobilise and motive. Finally, we will examine the difficulties to implement it and its limitations before concluding. 
- Adaptability. As we recommend doing at project level, we constructed the method respecting the principles of management by finalities. The objectives of the method are firstly to build a design project that will satisfy the finalities of the project and those of the participants in the design process, then subsequently to facilitate the implementation and development of the project. These overall objectives of the method were then deployed in the form of phase and stage objectives. We currently recommend tools that we adapted and tested, and which enabled us to achieve these objectives. It is nevertheless advisable to adapt this choice in accordance with the context of the project, the corporate culture of the firms involved, and the knowledge and experience of the members of the project team. This flexibility of the method, which does not impose any specific tool, is an asset for the firms and project teams. The reasoning in terms of objectives impose no constraints on means, only the result is measured. These means are chosen by the project team for their effectiveness, but also because they are appropriate, are pert of their culture, and that of the company's; they are therefore recognised and relevant. This construction enables the method to enrich itself constantly through the feedback provided by experience.

- Operability. The implementation of this method enabled us to confirm our hypotheses concerning decision-making. The confrontation of the two elements, finalities and perceived situation, enables elaboration followed by the effective management of the project to the satisfaction of all participants. Its aptitude for assisting the project team, for programming its intervention, for transforming the finalities of a problem into a concrete solution, was confirmed over the course of our projects. The method facilitates the decision-making process over the entire duration of the project. On a more general ground, usual difficulties encountered when implementing new design methods such as its suitability with company culture (Filson and Lewis 2000) are mostly overcome because the method is proposed by the design team itself. Its ability to yield data on the current design process with a view to the capitalisation of knowledge and expertise remains to be studied in more detail.

- Creative potential. The concept of flexibility and method of project management by finalities releases the project teams from the straitjacket that is usually imposed on them. Although we observed that most teams used classic methods to begin with, we also observed a number of relevant and original adaptations and additions. The creative freedom given to the designers enables them to reveal their creative potential as the different projects progress. It will no doubt engender savings of time and costs and boost performance.

We believe that this method, through its rigorous and systematic approach, enables the subjective aspect of the perception of risks and associated benefits to be taken into account. This has the consequence of federating the participants around a common project and convincing executive management to commit themselves and support the project. We observed that project managers liked this simple and useful project management tool and that the operational managers were highly satisfied with its effectiveness.

\subsection{Capacity to mobilise and motivate: give new meaning to projects}

As we observed, faced with the ever increasing complexity of design projects, engineers and managers tended to rationalise - to increase the number of procedures and methods to be followed - to the detriment of creativity, reactivity and effectiveness, leading to a loss of meaning. It appears that in the current climate one no longer designs a product; rather, one applies a recipe or procedures.

To respond to the growing number of tools and methods, generating ever more information, we need an anthropocentric approach, compatible with the cognitive patterns of designers, which will enable them to regain a sense of the meaning of their actions. Through the structured, 
yet flexible approach that we chose, we are able to amplify our capacity to reason and to process information, and thereby to make decisions that are more effective. All actions taken based on the method have a sense of meaning as they inevitably help the project to progress towards its finalities. This approach ensures a gain in intelligibility, in communicability, in cognitive ergonomics. It restores a sense of meaning, a raison d'être, to each of the tasks carried out by the participants by demonstrating that the task contributes to the effective progress of the project towards its finalities. In so doing, it contributes to the motivation and mobilisation of the participants.

\subsection{Difficulties and limitations}

Taking perspective and anticipating necessitate an investment of time and money and it is not always easy to calculate the return on investment; it requires a freedom of mind that is hard to find in the face of everyday pressures. This state of affairs renders the principle of anticipation difficult to apply.

We also have to confront management habits. The 'hierarchy' is used to 'fixing' objectives and 'making the decisions'. This type of management can feel cheated or think it is losing its authority during the phases of construction of the finalities in teams. The sharing of information and decisions can sometimes prove difficult.

However, the initial comments that we have on the mode of application of the method shows a certain initial reticence to examine and formally expose the risks of dysfunction of a project. Furthermore, the difficulty in imagining the consequences of these dysfunctions, in calling on experiences that are not always easy to transpose, can sow the seeds of doubt over the efficacy and therefore the usefulness of the method. But, beyond these initial difficulties in accepting the method, we observed that the fact of involving members of the team in the construction of 'their own' project and calling on their abilities to anticipate risks, motivated them to persevere in the application of the method.

Finally, if the construction of a common culture enhances collective efficacy, and if the construction of a project in terms of its finalities improves motivation and a sense of belonging to the project, by contrast individual efficacy rests largely on the competence of each person. This aspect is not dealt with by the method we have presented and constitutes a limit on the possibilities for development of new products. It depends particularly on the policy of training and personnel development adopted by individual companies.

\section{Conclusion}

The presented method has already demonstrated its efficacy during trials on several different projects. It enables the identification of risks associated with new product design projects, and in particular it enables us to ensure that these risks are dealt with in an effective manner. This method is designed for project managers and their teams. It is generally implemented after the pre-project phase is finished, the decision to launch the project has been made, and the execution of the project has been entrusted to the project manager by executive management. The project manager must then define and construct the project, and then execute it, implement it, lead it to completion. It is during the two essential phases of construction/definition and execution/accomplishment that the method can be applied. The earlier in the phase of construction/definition the method is used, the more substantial its contribution and the greater its efficacy. 
We are currently studying the possibility of adapting the method to the needs of the directorates of research, development and innovation of companies and project directors for application to the upstream pre-project phases and the management of portfolios of projects.

\section{References}

Association Français d' analyse de la Valeur (AFAV), Qualité en Conception, La Rencontre Besoin-ProduitRessources, 1997 (Afnor).

Association Française des Ingénieurs et Techniciens en Plannification (AFITEP), Le management de projet, principe et pratique, 2nd edition, 1998 (Afnor).

Aoussat, A., Christofol, H. and Le Cop, M., The new product design - a transverse approach. J. Engrg. Dsn., 2000, 11(4), 399-417.

Boursin, J.-L., La Décision Rationnelle, 1996 (Economica: Paris).

Chachuat, J., Actes du Colloque IQM, 8 octobre 1998.

Chauvel, A.M., Méthode et Outils pour Résoudre un Problème, 1996 (Dunod: Paris).

Checroun, A., Comprendre, Concevoir Et Utiliser Les Siad, 1992 (Editions Masson: Paris).

Christofol, H., Modélisation systémique du processus de conception de la coloration d'un produit. Thése de doctorat, Spécialité génie industriel, Ecole Nationale Supérieure d'Arts et Métiers, Paris, 1995.

Chvidchenko, I. and Chevalier, J., Conduite et Gestion de Projets, 1994 (Cépaduès Editions: Toulouse).

Crozier, M. and Friedberg, E., L'acteur et le Système, 1977 (Editions du Seuil).

Darses F., L'ingénierie concourante: un modèle en meilleure adéquation avec le processus cognitif de conception, In Ingénierie concourante: de la technique au social, edited by P. Bossord, C. Chanchevrier and P. Leclair, 1997 (Economica: Paris).

Eder, W.E., Design modelling-a design science approach (and why does industry not use it?) J. Engrg. Dsn., 1998, 9(4), 355-371.

Filson, A. and Lewis, A., Cultural issues in implementing changes to new product development process in small to medium sized enterprise (SME). J. Engrg. Dsn., 2000, 11(2), 149-157.

Frost, R.B., A suggested taxonomy for engineering design problems. J. Engrg. Dsn., 1994, 5(4), 399-410.

Gautier, R., Qualité en conception: proposition d'une méthode de fiabilisation du processus de traitement de l'information. Thèse de doctorat, Spécialité Génie Industriel, Ecole Nationale Supérieure d'Arts et Métiers, 1995.

Gautier, R., Truchot, P. and Gidel, T., Method of reliability analysis in the project information management process. In IPMA International Symposium on Project Management 1997-Risks in Projects and Project Oriented Business, 17-19 September 1997, Helsinki.

Genelot, D., Manager dans la Complexité, 1998 (INSEP Edition: Paris).

Ghertman, L., La Prise de Décision, 1981 (IRM/PUF: Paris).

Giard, V. and Midler, C., Pilotages de Projet et Entreprises, 1993 (Economica: Paris).

Hubka, V. and Eder, W.E., Design Science: Introduction to the Needs, Scope and the Organisation of Engineering Design Knowledge, 1996 (Springer-Verlag: London).

Kast, R., La Théorie de la Décision, 1993 (La Découverte: Paris).

Laplane, J.-P., Les Cahiers du Management $N^{\circ}$ 2, 1995 (IQM: Paris).

Laroche, H. and Nioche, J.P., L'approche cognitive de la stratégie d'entreprise. Revue Française de Gestion, 1994, juin-julliet-août, 99, 64-78.

Le Moigne, J.-L., Les Systèmes de Décision dans les Organisations, 1974 (PUF: Paris).

Le Moigne, J.-L., La Modélisation des Systèmes Complexes, 1990-1995 (Dunod: Paris).

Louyot, G., Prise en compte des risques dans les projets de développement de produits. Thèse de doctorat, Spécialité Génie Industriel, Ecole Nationale Supérieure d'Arts et Métiers, 1997.

Maffin, D., Engineering design models: context, theory and practice. J. Engrg. Dsn., 1998, 9(4), 315-327.

March, J.G., Décision et Organisations, 1991 (Edition Organisation).

Melese, J., Approches Systémiques des Organisations, vers L'entreprise à Complexité Humaine, 1990 (Les Editions d'Organisation: Paris).

Munier, B., Décision, Encyclopoedia Universalis, 1993 (Corpus 7: Paris).

Paulre, B., Entreprises-Systéme-L'entreprise est-elle vraiment un système? In Systémique, Théorie et Application, Technique et Documentation, 1992 (Lavoisier: Paris).

Perigord, M., Les Parcours de la Qualité, 1997 (Afnor: Paris).

Pomerol, J.-C. and Barba-Romero, S., Choix Multicritère dans L'entreprise, Principe et Pratique, 1993 (Hermés: Paris).

Roy, B. and Bouyssou, D., Aide Multicritère à la Décision: Méthodes et Cas, 1993 (Economica: Paris).

Russo, E.J. and Schoemaker, P.J.H., Les Chausse-Trappes de la Prise de Décision, 1994 (Les éditions d'Organisation: Paris).

Saaty, T.L., Décider Face à la Complexité: Une Approche Analytique Multicritére D'aide à la Décision, 1984 (Entreprise Moderne d'Edition: Paris).

Sfez, L., Critique de la Décision, 1992 (Presses de la fondation nationale des sciences politiques: Paris).

Shiba, S., Le Management Par Percée, 1995a (INSEP Editions: Paris). 
Shiba, S., Les Outils du Management de la Qualité, 1995b (MFQ: Paris).

Simon, H.A., Libres propos sur la prise de la décision et son apprentissage. In Revue Française de Gestion, 1993, juin-julliet-août, 94, 112-116.

Simon, H.A., The new science of management decision. In Traduit en Français: Le Nouveau Management: la Prise de Décision par les Ordinateurs, 1977-1980 (Economica: Paris).

Thepot, J., Gestion et Théorie des Jeux: L'interaction Stratégique dans la Décision, 1988 (FNEGE, Vuibert: Paris).

Therrien Eyquem, M.-C., Introduction aux cindyniques. Ouvrage collectif, Edition ESKA, 1998.

Truchot, P., De l'approche pluridisciplinaire de la conception de produit vers une science de l'innovation, Rapport de synthèse en vue d'obtenir l'habilitation à diriger les recherches, Institut polytechnique de Lorraine ENSGSI, 1997.

Ullman, D.G., Robust decision-making for engineering design. J. Engrg. Dsn., 2001, 12(1), 3-13.

Vadcar, P., Aide à la programmation de l'utilisation des outils en conception de produit. Thése de doctorat, Spécialité Génie Industrielle, Ecole Nationale Supérieure d'Arts et Métiers, Paris, 1996.

Vigier, S., Les Cahiers du Management $N^{\circ}$ 2, 1995 (IQM).

Yazdani, B., Holmes, C., Four models of design definition: sequential, design centered, concurrent and dynamic. J. Engrg. Dsn., 1999, 10(1), 25-37.

\section{Norms}

ISO9000, Quality Management Systems - Fundamentals and Vocabulary, 2000.

ISO10006, Quality Management Systems - Guidelines for Quality Management in Projects, 1997.

NF X50-100, Analyse fonctionnelle-Caractéristiques fondamentales, 1996.

F X50-105, Le management de projet, concepts, 1991. 
